\title{
Quality life evaluation after mastectomy or Quart
}

\author{
Adriana Cordova ${ }^{1}, G^{\prime}$ iovanni Maria D'Antonio ${ }^{1}$ \\ 1 University of Palermo
}

Funding: The author(s) received no specific funding for this work.

Potential competing interests: The author(s) declared that no potential competing interests exist.

\section{Abstract}

Breast cancer is a worldwide diffused disease and represents the most common tumor among women. Due to great improvements in prevention protocols and imaging, most patients are diagnosticated with non-advanced disease and can either be treated with mastectomy or quadrantectomy/lumpectomy plus adjuvant radiotherapy (QUART). Both procedures yield similar outcomes in terms of disease free survival, hence greater attention is been drawn towards improving patients' quality of life following treatment. The purpose of the present retrospective, monocentric study is to assess whether there is a significant difference between the radical (mastectomy with immediate reconstruction) and conservative (QUART) ways of treating breast cancer in terms of patient's perception of disease and quality of life using the BREAST-Q questionnaire.

Despite continuous improvements in terms of prevention, diagnosis and treatment, breast cancer still represents a challenge considering new cases number per year and the social and psychological impact of this cancer for women. Most cases of breast cancer are diagnosticated in a non-advanced stage due to screening programs that have enabled a substantial reduction of mortality over the years worldwide. Non advanced breast cancers are typically treated with two alternative procedures: mastectomy or quadrantectomy/lumpectomy plus adjuvant radiotherapy (QUART). As we know, the scientific literature doesn't highlights significant differences in terms of disease free survival between these two procedures ${ }^{1}$, so the application of one or the other procedure mainly depends on surgeons experience and choices ${ }^{2}$. Quadrantectomy is usually indicated when the primary tumor is less than $2 \mathrm{~cm}$ associated to a medium/large breast size; whereas subcutaneous mastectomy ( or nipple sparing mastectomy) is indicated in women with a small/medium breast size, as long as the tumor is localized to more than $1 \mathrm{~cm}$ to the areola $^{3}$. Within the framework of conservative mastectomies, valid alternatives to the quadrantectomy are also the skin sparing mastectomy ${ }^{4}$, that entails the nipple areola complex sacrifice, is indicated when the tumor is localized to less than $1 \mathrm{~cm}$ to the areola, and skin reducing mastectomy ${ }^{5}$, indicated in women with medium/large breast size and moderate to severe breast ptosis grade. Despite these considerations, mastectomy and quart reveal differences in long term quality of life and psychological effects ${ }^{6}$. QUART is viewed as breast-conserving surgery; the goal is to remove the cancer and some of the surrounding 
normal breast tissue but leaving the breast intact. The mastectomy, on the other hand, removes the entire breast. Despite QUART leaves the breast intact, it may result in aesthetic breast defects due to radiotherapy skin effects and quadrantectomy/lumpectomy. Instead mastectomy followed by reconstruction, especially the autologous reconstruction, ensures a better aesthetic outcomes, although losing the entire breast can lead to a greater psychological discomfort. ${ }^{7}$ The purpose of our study is to compare QUART and mastectomy in terms of patient's perception of disease and quality of life using the BREAST-Q questionnaire in about 300 patients who undergone one or the other procedure among 2017-18 in our breast unit. The BREAST-Q is a rigorously developed patient-reported outcome measure for use in cosmetic and reconstructive breast surgery and clinical practice ${ }^{8}$. Evaluating two principal domains of the BREAST-Q, quality life and patient satisfaction can help to indicate an eventual superiority of one or the other procedure on patient's quality of life.

\section{References}

1. Veronesi, U., Volterrani, F., Luini, A., Saccozzi, R., Del Vecchio, M., Zucali, R., Galimberti, V., Rasponi, A., Di Re, E., Squicciarini, P., \& Salvadori, B. (1990). Quadrantectomy versus lumpectomy for small size breast cancer. In European Journal of Cancer and Clinical Oncology (Vol. 26, Issue 6, pp. 671673). Elsevier BV. https://doi.org/10.1016/0277-5379(90)90114-9

2. Huang, Y., Wu, H., \& Luo, Z. (2017). A retrospective study of optimal surgical management for occult breast carcinoma. In Medicine (Vol. 96, Issue 52, p. e9490). Ovid Technologies (Wolters Kluwer Health). https://doi.org/10.1097/md.0000000000009490

3. Nava, M. B., Catanuto, G., Pennati, A., Garganese, G., \& Spano, A. (2009). Conservative Mastectomies. In Aesthetic Plastic Surgery (Vol. 33, Issue 5, pp. 681-686). Springer Science and Business Media LLC. https://doi.org/10.1007/s00266-009-9382-4

4. Galimberti, V., Vicini, E., Corso, G., Morigi, C., Fontana, S., Sacchini, V., \& Veronesi, P. (2017). Nipplesparing and skin-sparing mastectomy: Review of aims, oncological safety and contraindications. In The Breast (Vol. 34, pp. S82-S84). Elsevier BV. https://doi.org/10.1016/j.breast.2017.06.034

5. Moo, T.-A., Sanford, R., Dang, C., \& Morrow, M. (2018). Overview of Breast Cancer Therapy. In PET Clinics (Vol. 13, Issue 3, pp. 339-354). Elsevier BV. https://doi.org/10.1016/j.cpet.2018.02.006

6. Majewski, J. M., Lopes, A. D. F., Davoglio, T., \& Leite, J. C. de C. (2012). Qualidade de vida em mulheres submetidas à mastectomia comparada com aquelas que se submeteram à cirurgia conservadora: uma revisão de literatura. In Ciência \& Saúde Coletiva (Vol. 17, Issue 3, pp. 707-716). FapUNIFESP (SciELO). https://doi.org/10.1590/s1413-81232012000300017

7. Zhang, C., Hu, G., Biskup, E., Qiu, X., Zhang, H., \& Zhang, H. (2018). Depression Induced by Total 
Mastectomy, Breast Conserving Surgery and Breast Reconstruction: A Systematic Review and Metaanalysis. In World Journal of Surgery (Vol. 42, Issue 7, pp. 2076-2085). Springer Science and Business Media LLC. https://doi.org/10.1007/s00268-018-4477-1

8. Pusic, A. L., Klassen, A. F., Scott, A. M., Klok, J. A., Cordeiro, P. G., \& Cano, S. J. (2009). Development of a New Patient-Reported Outcome Measure for Breast Surgery: The BREAST-Q. In Plastic and Reconstructive Surgery (Vol. 124, Issue 2, pp. 345-353). Ovid Technologies (Wolters Kluwer Health). https://doi.org/10.1097/prs.0b013e3181aee807 